\title{
Managing uncertain consequences of a global crisis: SMEs encountering adversities, losses, and new opportunities
}

\author{
Hamid Etemad ${ }^{1}$ \\ Published online: 10 July 2020 \\ (C) Springer Science+Business Media, LLC, part of Springer Nature 2020
}

\section{Introductions}

The release of this issue coincides with the time that humanity is encountering a global crisis and unprecedented uncertainties. The coronavirus (COVID-19) has exposed the world to uncertainties that have not been experienced before. More than 190 countries, more than 10 million people, ${ }^{1}$ have been infected and for the past 6 months, country-after-country has been inflicted by the COVID- $19^{2}$ pandemic at different levels, each imposing massive costs and unfathomable uncertainties. Countries as a whole, and their national and local governments, faced the pandemic crisis underprepared, if not unprepared, and found no time to prepare adequately. Metropolises, large cities, and even small cities faced the challenge of dealing with a fast-expanding world-wide pandemic, engulfing nearly all population centers. Nearly all institutions were affected to varying degrees, but small- and mediumsized enterprises (SMEs) and especially internationalized (iSMEs) suffered the most.

The COVID-19 did not respect any boundary conditions. Practically no country government, regardless of the level, or location, was spared. Many national health-care systems, known previously for their renowned capabilities and care, were overwhelmed and lost infected patients at rates never experienced before. Some ran out of the crucial facilities and resources, including hospital beds, intensive care units (ICU), and necessary medical equipment, and even fell short of life-saving medications. Practically all institutions sought to acquire the necessary equipment and replenish their rapidly depleting supplies to no avails, as suppliers could not ramp-up fast enough to respond to sharp spikes in demand. Even when suppliers could ramp-up production to produce

\footnotetext{
${ }^{1}$ Source: https://www.worldometers.info/coronavirus/countries-where-coronavirus-has-spread/visited on June 10, 2020.

${ }^{2}$ The World Health Organization (WHO) called the coronavirus with the acronym of COVID-19 and declared the crisis as a pandemic on March 11,2020, and preventative locked-down started soon after, if not earlier.
}

Hamid Etemad

hamid.etemad@mcgill.ca

1 McGill University, Montreal, Canada 
more and faster, they faced uncertainties concerning the length of time that the higher demand would continue to justify the additional investments.

The phenomenon of newly found (or lost) opportunities and associated uncertainties occupied most SMEs. Generally, SMEs depend intensely on their buyers, supplies, employees, and resource providers without much slack in their optimally tuned value creation system. A fault, disruption, slow-down, strike, or the likes anywhere in the system would travel rapidly upstream and downstream within a value creation cycle with minor differences in its adverse impact on nearly every member. When a crisis strikes somewhere in the value creation stream, all members would soon suffer the pains. Consider, for example, the impact of national border closures on international supplies and sales. Generally, disruptions in logistics, including international closures, could stop iSMEs' flow of international supplies and, after the depletion of inventories, shipping and international deliveries would be forced to stop, which in turn would be exposing nearly all other members of the value-net slow-downs and stoppages indirectly, if not directly, sooner rather than later. In spite of many advantages of SMEs relying on collaborative international networks, the COVID-19 crisis pointed out that all members will need to devise alternative contingency plans for disruptions that may affect them more severely than otherwise.

The rapidly emerging evidence suggests that the capable, far-sighted, and innovative enterprises perceived the slow-downs, or stoppages in some cases, as an opportunity for starting, or increasing, their alternative ways of sustaining activities, including on-line and remote activities and involvements, in order to compensate for the shrinkage in their pre-COVID demands, while the short-sighted or severely resource-constrained SMEs faced the difficult decision of closure in favor of "survival or self-preservation" strategy, thus losing expansion opportunities. ${ }^{3}$

The silver lining of the COVID darkness is that we have collectively learned invaluable lessons that deserve a review and re-examination from entrepreneurial and internationalization perspectives in order to prepare for the next unexpected crises, regardless of its cause, location, magnitude, and timing. In few words, the world experienced a crisis of massive scale for which it was unprepared and even after some 6 months there is no effective remedial strategy (or solution) for crises caused by the COVID-19 pandemic in sight.

The inevitable lesson of the above exposition is that even the most-prepared institutions of the society's last resort nearly collapsed. Given such societal experiences, the sufferings of industries and enterprises, especially smaller ones, are understandable and the scholarly challenge before us is what should be researched and learned about, or from, this crisis to avoid the near collapse of smaller enterprises and industries, on which the society depends and may not easily absorb another crisis of similar, or even smaller, scale. ${ }^{4}$

The main intention of this introduction is not to review the emergence and unfolding of a major global crisis that inflicted massive damage on SMEs in general and on iSMEs in particular, but to search for pathways out of the COVID-19's darkness to brighter horizons. Accordingly, the logical questions in need of answers are:

\footnotetext{
${ }^{3}$ While the world-wide stock market indices have lost value in 2020 so far, the general index of hightechnology and the Internet-based companies has increased more than $15 \%$ in the past 6 months.

${ }^{4}$ Many countries and regions are experiencing the second wave of the COVID, which is paralyzing the affected member and institutions the were adversely impacted earlier.
} 
1 Were there strategies that could reduce, if not minimize, the adverse impact of the crisis.

2 Could (or should) SMEs or iSME have prepared alternative plans to protect themselves or possibly avoid the crippling impact of the crisis.

3 Why were SMEs affected so badly.

4 Are there lessons to be learned to fight the next one, regardless of location, time, and scale?

In spite of the dominating context of the ongoing and still unfolding COVID-19 crises, there is a need to learn about the world's both effective and difficult experiences at this point in time, which are beyond the aims and scope of this journal. Rather, it aims to analyze and learn about the bright rays of light that can potentially enlighten entrepreneurial and human innovative ingenuity to find pathways from the darker to the brighter side of this global and non-discriminatory crisis, within the scope of international entrepreneurship. Naturally, in seeking those pathways, one is expected to encounter barriers, obstacles, and institutional rigidities that could still pose nearly insurmountable challenges to the society, and especially to SMEs and iSMEs, have experienced in the past which were partially due to endemic rigidities (Aparicio et al. 2016; North 1990). On the positive side of the ledger is that many of the above adverse factors are among the host of smaller crisis-like challenges that entrepreneurial enterprises face regularly and manage to bridge across them to realize fertile and promising opportunities. Learning how such bridges are built and maintained not only is entrepreneurial, but also may help the causes of humanity by showing the way out of this, and other similar, crises. This will be a noble objective if it can be accomplished, which should motivate many to take up corresponding challenges in spite of the low chances of its success. We will return to this topic at the end of this article.

A cautionary note It is very important to note that the next four articles appearing in this issue were neither invited for this issue nor received any special considerations. They are included in this issue as they offer concepts, contents, contexts, and issues that are relevant to the overriding theme of this issue and may assist SMEs trying to manage a crisis facing them and scholars interested in investigating related issues. Without exceptions, they were subjected to the journal's rigorous and routine double-blind peerreview processes prior to their acceptance. They were then published in the journal website's "On-line First" option waiting for placement in an issue with a coherent theme drawing on the research of each and all the selected articles for that issue. The highlights of the four articles that follow are presented in the next section of this article. They offer promising argument and plausible pathways based on their scholarly research relevant to an emerging or unfolding crisis.

Structurally, this article comprises five parts. A developmental discussion of uncertainties and their types, causes, and remedies as well as enabling topics relating to crisis-like challenges follows this brief introduction in "Developmental arguments." A brief highlight of each of the four articles appearing in this issue, and their interrelationships, will be presented in "The summary highlight of articles in this issue." "Discussions" provides discussions related to the overriding theme of this article. Conclusion and implications for further research, management, and conducive public policy will appear at "Conclusion and implications." 


\section{Developmental arguments}

The extra-ordinary socio-economic pains and the added stress of the COVID-19 crisis exposed entrepreneurs, SMEs, larger enterprises, and even national governments to unprecedented conditions and issues. As stated earlier, there is a need for understanding how and why it became such a major world crisis and what factors contributed to expanding and amplifying its impact in the early quarters of the year 2020. Although the primary aim of this issue is not reviewing the crippling impact of the COVID-19 crisis, for it is done elsewhere (e.g., Etemad 2020; Surico and Galeotti 2020), some of its influential factors emerged and stood out in the early days of 2020 that effected international business and entrepreneurial institutions from the very beginning; and yet, it took some time to enact defensive private and public actions against it. Although COVID-19 was not the first world-wide health crisis, many enterprises, one-afteranother, were defenselessly affected by it, even after a few months. While we have learned about some of the contributing factors to this expansive crisis, we are still in the dark as to why the broader community, and even resourceful enterprises, had failed to foresee the emergence and unfolding of such a crisis (Surico and Galeotti 2020) or prepare potential defenses against it. The crisis' high magnitude and broad scope involved nearly everyone worrying and learning about its impact first-hand as it unfolded; but it appears that top management teams (TMTs) had not learned fully from the past or taken precautions against the emergence of potential crises, and for this one, in a timely fashion. ${ }^{5}$ However, the literature of managing a major crisis of the past, mainly in the large enterprises, has pointed out a few known forces, or potential factors, and issues that had contributed to past crises and are briefly reviewed below as follows.

Uncertainties As similar broad world-wide crisis-like challenges involving nearly all institutions have not been experienced in the recent past, enterprises and especially smaller firms found themselves unprepared and encountered high levels of discomfort and taxing uncertainties in their daily lives. Generally, such effects are more disabling when enterprises are in the earlier stages of their life cycle when they suffer from lack of rich experience to guide them forward, and they do not have access to the necessary capabilities and resources to support them through (Etemad 2018a, b, 2019). Entrepreneurial enterprises that have already internationalized, or aspire to internationalize, encounter the customary risks and uncertainties of "foreignness" (e.g., Hymer 1967; Zaheer 1995; Zaheer and Mosakowski 1997), lack of adequate "experiential experience"(e.g., Eriksson et al. 1997; Johanson and Vahlne 1977), "outsidership" (Johanson and Vahlne 2009), and the liability of "newness" (Stinchcombe 1965). The COVID crisis added risks and uncertainties arising from national lockdowns, unprecedented regulatory restrictions, closure of international borders not experienced since the Second World War, the near collapse of international supply chains and logistics, among many others, most of which became effective without much prior notice, and each of which alone could push smaller enterprises to the edges of demise

\footnotetext{
${ }_{5}^{5}$ Generally, the top enterprise management teams (TMTs) are somewhat isolated from the direct impact of smaller crises as it is unfolding and may not experience its full impact. Consider, for example, that lower echelon managers and employees were fired or laid-off while the firm's CEO and members of the top management team were not directly affected nor suffer similarly.
} 
due to the consequent shortages, operational dysfunctions, closure, and potential bankruptcies. Survival during the heights of the COVID-19 crisis required rapid strategic adaptations, mostly technological, and use of alternative online facilities, capabilities, and novel strategies to reach stakeholders (customers, supplier, employees, investors, and the likes) to quickly compensate, if not substitute, for their previous arrangements that had become dysfunctional. Smaller firms that had prepared alternative contingency plans, supported with reserved dynamic capabilities and resources (Eisenhardt and Martin 2000; Jantunen et al. 2005), viewed the dysfunctionality of rivals as opening opportunities and managed rapidly a successful transition to exploit them in a timely fashion, either through their own or through established others' functional "platform-type operations" (e.g., Amazon, Alibaba, Shopify, Spotify, and many similar multi-sided platforms). They were viewed by others as exceptional, progressive, even somewhat "disruptive" (Utterback and Acee 2005) and creatively destructive to others (Chiles et al. 2007) in some cases as internationalized firms restrategized and refocused on their domestic markets in reaction to the closure of border and international logistics dysfunctions. ${ }^{6}$ However, such adaptations, deploying innovative and additive technologies and other innovative Industry 4.0 (e.g., additive technologies, artificial intelligence, Internet of Things (IOT), robotic, 3-D printing, and other I. 4.0 technologies) (Hannibal 2020, forthcoming) or collaboration with established on-line or off-line establishments, faced their own unexpected operational difficulties nationally, while their counterparts experienced them internationally, including "cross-cultural communication and misunderstandings" (Noguera et al. 2013; Mitchell et al. 2000; McGrath et al. 1992), national and international logistic problems, supply chain disruption, among many others, mostly attributable to COVID-related restrictions. Among such unexpected international factors were forced rapid change in consumer behavior and national preferences in exporting countries (verging on implicit discriminatory practices ${ }^{7}$ ), worsening diplomatic relations, rising international disputes, regulatory restriction, and a host of other well-documented causes, exposing firms to unforeseen risks and uncertainties not experienced for decades. Therefore, the concepts of risk, uncertainty, and the way for mitigating, or getting over, true or perceived crises deserve discussion as they are pertinent to resolving crisis-like challenges facing smaller firms, regardless of their particular timing and situation. Similarly, factors contributing to, or mitigating against, the experience level(s) of ex-ante unknowns, or "un-knowables" (Huang and Pearce 2015), contributing to uncertainties merit equal

\footnotetext{
${ }^{6}$ Reportedly, rapidly growing internationalized medium-sized enterprises reconfigured and redeployed parts of their facilities rapidly to fabricate and provide goods locally to reduce shortages in products previously imported from international markets. For example, Canada Goose, manufacturer of luxury winter clothing, began making personal protective garments for hospital staff (see an article entitled as "TORONTO - Canada Goose Holdings Inc. is moving to increase its domestic production of personal protective equipment for health-care workers across Canada at https://globalnews.ca/news/6798844/canada-goose-production-medicalppe-coronavirus/ visited on April 19, 2020). Similarly, many other companies, including CCM Sporting Equipment and Yoga Jeans, began producing protective visors, glasses, and gowns for essential workers and hospital staff members (see article entitled as "Quebec companies answer the call to provide protective equipments" at https://montrealgazette.com/business/local-business/masks-and-ppes... - visited on June 8, 2020). For all of the above companies, their sales required very different distribution channels, such as pharmacies and hospital supply companies that are far from clothing and sport equipment.

7 The US-based 3M was ordered not to ship N95 face mask to Canada in March-April 2020. Similarly, some Chinese suppliers refused to ship previously placed and paid-for ordered supplies.
} 
considerations. Nearly all articles appearing in this issue relate to such contributing factors and offer different bridging pathways, if not causeways, over the sea of scholarly challenges faced by international entrepreneurs in quests for their success in entrepreneurial internationalization.

In the context of the ongoing crisis, the pertinent discussion of uncertainties is extensive (Liesch et al. 2014; Bylund and McCaffrey 2017; Coff 1999; Dimov 2018; Dow 2012; Huff et al. 2016; Liesch et al. 2014; Matanda and Freeman 2009; McKelvie et al. 2011; McMullen and Shepherd 2006) and ranges from one extreme to another classic view at the other extreme-namely, from the Akerlofian cross-sectional (Akerlof 1970) to the Knightian longitudinal uncertainties (Knight 1921). At the root of both is in the absence of objective, or reliable information and knowledge with very different density distributions. The Akerlof's cross-sectional uncertainty relates to a relatively shorter term and the information and knowledge (Erikson and Korsgaard 2016) discrepancies (between or among agents) favoring those who have more of them and exposing those who have less, or lack of them. Consider, for example, the case of buying a used car (or second-hand equipment). Generally, the seller has more reliable, if not near perfect, knowledge about the conditions of his offerings in terms of its age, performance, repairs, faults, and the likes than a potential buyer who will have to assume, predict, or perceive the offer's conditions without reliable information in order to justify his decision to either buy the car (or the equipment) or not. The potential buyer may ask for more detailed information about the offers' conditions or seek assurances (or even guarantees) against its dysfunctions to pursue the transaction or not when he is in doubt. The noteworthy point is that the objective information(or knowledge) is available but the buyer cannot access it to assess it objectively - thus, the cross-sectional uncertainty is due to the asymmetric state of information and knowledge among parties involved in a transaction (Townsend et al. 2018), which clears soon after the transaction is consummated. In Williamson's transaction cost approach (Williamson 1981), such discrepancies are viewed as transaction frictions between the parties, where at least one party acts opportunistically to maximize self-interest at the cost to the other(s), while the other party(ies) is incapable of securing the necessary objective information to form the required knowledge for enabling a prudent decision.

Within the uncertain state of COVID-19 crisis, both of the above phenomena (asymmetry and opportunistic behavior) were clearly observable and contributed to creating subsidiary crises of different magnitudes-relatively larger ones for smaller enterprises and smaller ones for the larger companies, some of which were unduly amplified due to the lack of objective information and opportunistic behavior at the time. Retrospectively, we collectively learned, for example, that there was no worldwide shortage of health-care equipment and supplies but major suppliers, or intermediaries, withheld their supplies and did not ship orders on time as they usually would have previously done, which created the perception of acute shortages forcing prices higher, knowing well that buyers were incapable of assessing the true availability of inventoried supplies for demanding lower prices, especially when the richer buyers (e.g., national governments) were willing to bid-up prices due to urgency of their situations. This is not far from a discriminating monopolist taking advantage of its uninformed buyers. Similar situation happens when a small company fails to plan for contingencies to cover for emerging uncertainties by ordering just sufficient for their regularly needed supplies (e.g., the minimum order quantity) to minimize the short- 
term costs of holding inventory. The longer term overall costs of over-ordering to build contingency supplies is the cumulative cost of holding excess inventory over time, which could be viewed as an insurance premium for avoiding supply shortages, or stock-outs, while the true costs of such internal imprudent strategies become much higher when, for example, potential customer switch to other available brands, or there are uncertain and adverse external conditions, including artificially created shortages, as discussed earlier. Generally, the top management of resource-constrained smaller companies aims to ensure the efficiency of their resources, including supplies, and to preserve adequate cash flows, to avoid short-term uncertainties of insolvency, akin to the Akerlofian type (Akerlof 1970).

In contrast, the absence of reliable information (or assurances) about steady supplies may contribute to, if not cause, a change in potential buyers' consumer behavior and further contribute to suppliers' over-estimation of buyers' demand trajectory over a longer time period fearing from facing acute adverse conditions such as those discussed in the previous case. However, such internal (e.g., management oversights) or external (e.g., suppliers withholding shipments or change in consumer behavior) causes due to absence of the required information, reliable forecasts or estimates, and imperfect knowledge over time begin to pertain more to Knightian uncertainties than Akerlofian types (i.e., across transacting agents, which is comparatively shorter term and more frequently encountered uncertainties).

The impact of resources and capabilities Naturally, a firm's level of resources (Wernerfelt 1984, 1995; Barney et al. 1991) or institutional inadequacies and restrictions (Bruton et al. 2010; North DC 1990; Kostova 1997; Yousafzai et al. 2015) may play influential roles in mitigation of encountered uncertainties. Consider, for example, the difference in abilities of smaller resource-constrained enterprises in continual need of minimizing fixed costs and larger and richer institutions (such as national governments) with higher priorities (than costs) to enforce performance contract(s). The richer resources of larger institutions pose a more credible threat of suing the supplier(s) lateron for potential damages of higher costs or delayed shipments than those of smaller firms, thus reducing the temptation for opportunistic behaviors (Williamson 2000) over time. As the transaction cost theory suggests (Williamson 1981), the ever-presence of such threats may dissuade suppliers from delaying and withholding shipments for the hope of higher revenues. Furthermore, even the opportunists may be exposed as other lower costs suppliers may realize the opportunities and respond with lower prices. ${ }^{8}$

Time, timing, and longer term uncertainties The above demonstrative discussions point to the critical role of timely-planned acquisition of capabilities and resources over time before emergencies, or shortages, become acute. The time dimension of this discussion relates to Knight's (1921) longitudinal uncertainties. The future is inherently uncertain; but one's needs and their corresponding transactions costs are more predictable at the time as, for example, transactions can be consummated at the prevailing prices. Delaying a transaction in the hope of buying at lower costs exposes the

\footnotetext{
${ }^{8}$ Given the critical influence of information, a brief Akerlofian type of information and information technology is presented next. However, there is a need for extensive Information and communication capabilities to reduce, and hopefully avoid, the adverse impacts of an unfolding crisis.
} 
transaction to longitudinal uncertainties, as the uncertainties' ex-post costs and the true prices are only revealed in the due course of time. Similarly, the longer term costs of preparedness and security can minimize the short-term costs to individual employees and other corporate persons. ${ }^{9}$ Accordingly, the intensity of a crisis, and its cumulative costs, may force national and local authorities to bid-up prices and absorb the much higher short-term costs at the time to ensure acquisition of essential supplies in order to avoid the difficult-to-predict costs of longitudinal uncertainties. For smaller enterprises, however, the state of their resources and the extent of prior experiences may influence their decision at the time. This will be discussed below.

Past experience and the firm's stages of life-cycle Generally, smaller and younger companies are short of excess resources and lack rich experience to provide them with a longer and far-sighted outlook for avoiding longitudinal uncertainties of the Knightian types by, for example, keeping a level of contingency inventories for difficult conditions and rainy days. However, even smaller start-ups with experienced serial entrepreneurs at the helm can benefit from the past experiences of their founding entrepreneur(s) through what Etemad calls as "the carry-over of paternal heritage" (Etemad 2018a) to enable planning and providing for their necessary resources.

The state of competition On one extreme, a monopolist can control supplies and create artificial shortages to force prices up in normal conditions. Under distress and unusual conditions, customers may bid-up prices to have priority access to the available supplies. In the perfect competition, on the other extreme, many suppliers compete to attract demand and prices remain relatively competitive due to highly elastic demands. Practically, however, the state of global competition is likely to be closer to a combination of regional oligopolistic (or monopolistic) competition and global competitive conditions, where suppliers perceive to have certain monopolistic powers to manipulate prices (e.g., due to their brand equity, location, or product quality), while they need to compete in a nearly hyper-competitive state (Chen et al. 2010) with other competitors who provide similar offerings. The knowledge of the competitive and institutional structures (Jepperson 1991; Yousafzai et al. 2015; Welter and Smallbone 2011) is, therefore, essential, especially to SMEs for deciding as optimally as possible, which all depends on both the buyers and suppliers state of information, communication, and knowledge, which is further discussed below.

The state of communication and information The advanced state of a firm's information and communication technology (ICT) is highly likely to enable it to decide prudently. As discussed earlier, uncertainties depend on one's state of reliable information impacting the achievement of optimality, which in turn depends on the state of information at the time. In short, a small firm's potential exposure to cross-sectional and longitudinal risks and uncertainties is also likely to depend on information on a combination of influential factors, some of which are discussed above; prominent

\footnotetext{
${ }^{9}$ Similar arguments apply to national preparedness and national security over time to shield individual and corporate citizens from bearing short-term or long-term high costs - the national costs per capita may pale relative to the immeasurable costs of human mortalities paid by the deceased people and their families, the massive unemployment, or high costs related to shortages in major crises, such as the COVID-19 pandemic.
} 
among such influential factors is reliable information about their operating context at the time and its probable trajectory in the near future. Furthermore, nearly all of the emerging advances in management and production, including additive technologies, depend heavily on information (Hannibal 2020, forthcoming) Finally, the next section will seek to discuss the above elements within the articles that follow.

\section{The summary highlight of articles in this issue}

This part consists of summary highlights of the contribution of the four double-blind, peer-reviewed articles with relevant materials to an emerging or an unfolding crisis. The second article in this issue is entitled "Muddling through Akerlofian and Knightian uncertainty: the role of socio-behavioral integration, positive affective tone, and polychronicity" and is co-authored by Daniel Leunbach, Truls Erikson, and Max Rapp-Ricciard. As discussed earlier, uncertainty and risk-taking propensity have been recognized as integral parts of general entrepreneurship for a long time (e.g., Gartner and Liao 2012) and this article focuses on studying them as they relate to individual entrepreneurs' affective socio-behavioral and also the way entrepreneurs function, including how they perceive their situation, manage, progress, and adjust their outlook within the environment(s) that exposes them to perceived risks and uncertainties. From an entrepreneurial perspective, a combined interaction of time and flow of information, or lack thereof, forming a knowledge base, is what entrepreneurial decisions depend. When the entrepreneurs need to make decisions without perfect cognition (based on his information and knowledge about the state of affairs at the time) within a relatively short time period, they and their decisions are exposed to an uncertain state of the world. Such uncertainty(ies) within a relatively short time span is (are) termed as crosssectional uncertainty. Generally, it is difficult to acquire nearly perfect information due to the shortage of time or the cost of searching for the information. George Akerlof (1970) suggested that such perceived uncertainty would not be as much due to lack of pertinent information as it would be due to the asymmetric distribution of information (Brown 2016) and the corresponding knowledge among agents - i.e., those who had more potent information and those who did not but needed it. Consider a typical entrepreneur in need of acquiring a good, or service, from a supplier or service provider, who has nearly perfect information about, or the knowledge of, the good or service he offers but does not fully disclose them to the entrepreneur in self-interest, which gives rise to the asymmetric distribution of the information (or knowledge) between the supplier and the potential buyer. Generally, this is also termed as "Akerlofian uncertainty."

Time is an important factor in entrepreneurial decisions, and the influence of time is as significant as the state of information. For example, the urgency of a decision deprives the entrepreneur of sufficient time for conducting informative research to enrich his state of information and forces the entrepreneur to decide earlier, rather than later, with some discomfort and reservation due to his insufficient information. ${ }^{10}$ With more time for acquiring sufficient information for forming a supportive knowledge

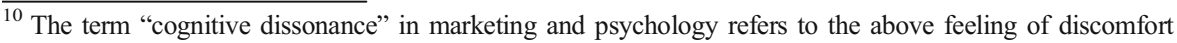
regarding the prevailing uncertainty.
} 
base, he can comfortably decide to consummate a particular transaction or not. The time cost of switching to another supplier or conducting research may increase the transaction costs and expose the transaction to longitudinal uncertainties as well.

In contrast to the asymmetric distribution of information across individuals in the short term (Brown 2016), the required time to acquire, or develop, the required information about the relevant state of affairs for forming the corresponding knowledge for portraying the future, or the near future, gives rise to longitudinal uncertainty, as suggested by Frank Knight's article in 1921 (Knight 1921) and is viewed as "Knightian uncertainty." Generally, the future is uncertain and it is not prudent to assume that it will be a linear extension of the current state of affairs, or alternatively, it will be predictable perfectly. Again, both the information and time are influential factors as more pertinent information is revealed over time.

Entrepreneurial start-ups, and new ventures, for example, suffer from both the shortage of time and information and thus offer fertile context for exploring not only the interaction of time and information, but also how new venture teams (NVTs) perceive the gravity of risks and uncertainties facing them. Therefore, exploring uncertainty within new venture teams, especially those based on new science and technology, which usually encounter higher uncertainties and commercialization risks, ${ }^{11}$ enables a deeper understanding of how uncertainties are perceived and managed by the new venture teams. As discussed in some length in the paper, the authors' research methodology enabled them to observe the impact of NVT's socio-behavioral and psychological characteristic and explore their reactions and response to both the shorter and longer term uncertainties facing them.

In the context of a major crisis, SMEs' top management teams (TMTs) suffer from both the inadequacies of information and shortage of time in most cases, neither of which they can control or extend into the future. In a major crisis, there are complex uncertainties with unclear prospects and come without prior warning-e.g., what will have an immediate adverse impact, will it increase or subside, how long will it last, and what will be the magnitude of accumulated damage when the crisis is nearly over? These are among many other questions that have no certain answers at the time. Similar to young start-ups, where founder-entrepreneurs suffer from shortages of time, knowledge (or reliable information), and resources, in addition to uncertainties associated with consumer behavior and market reactions as well as regulatory restriction, SMEs, and especially iSMEs, suffer from complex uncertainties for which they were not prepared, nor would they have sufficient time and resource to deal with the unfolding crisis satisfactorily. Furthermore, the normal sources of previous help and advice, including their social networks and support agencies, such as lenders, service providers, and suppliers, would be facing even larger problems of their own and incapable of assisting them in a timely fashion, which call for adequate alternative contingency plans for the rainy days as discussed earlier and further reviewed in a later section. This discussion points to a need for examining the potential role of environmental context in

\footnotetext{
${ }^{11}$ As compared with science-based start-ups, market-oriented start-ups have a clearer perception of demand in the marketplace. Science- and technology-based start-ups offer novel science and technology solutions to a range of problems, each of which require adaptation to solve the problem, which in turn pose higher commercialization uncertainties of theirs own. Therefore, science- and technology-based new ventures offer rich possibilities for examining NVT management of uncertainties facing them.
} 
increasing uncertainties or mitigating against them. The next article examines this very topic next.

The third article of this issue examines the context within which entrepreneurial decisions are made. It is entitled "Home country institutional context and entrepreneurial internationalization: the significance of human capital attributes" and co-authored by the team of Vahid Jafari-Sadeghi, Jean-Marie Nkongolo-Bakenda, Léo-Paul Dana, Robert B. Anderson, and Paolo Pietro Biancone. Nearly all decisions are embedded in a context, and the context for most international entrepreneurship decisions is perceived as more complex than those in the home market, as extensively discussed by internationalization literature. Internationalization involves at least two contextsone characterized by formal institutional structures and informal socio-cultural values (Hofstede 1983, 2001, 2011; Hofstede et al. 2010) at home, both helpful and restrictive, and the other at the host country environment, where each country's institutional structures differ from the others (Chen et al. 2017; Li and Zahra 2012). Even in the European Union's (EU) single market, where EU has increasing harmonized intercountry-wide regulatory and institutional requirements ever since $1993,{ }^{12}$ different local socio-cultural and behavioral forces influence decisions differently, especially those affecting consumer behavior and market-sensitive aspects, which are more deeply embedded in their country's institutional structures than others, encouraging or restricting certain entrepreneurial actions.

Generally, international entrepreneurship and their corresponding entrepreneurial actions are deeply embedded in their more complex contexts (Barrett, Jones, McEvoy, Granovetter 1985; Wang and Altinay 2012; Yousafzai et al. 2015) and highly internationalized SMEs (iSMEs), and even larger firms, need to respond sensitively to the various local (i.e., contextual) facets and adapt their practices accordingly (Welter 2011), which in turn add incremental complexities and expose the firm's early entrepreneurial, and especially marketing, to a higher degree of risk and cross-sectional uncertainties than those at home which is more familiar than elsewhere. However, firms learn from their host environment and also from their competitors as to how to mitigate their risks and remove the information (and knowledge) asymmetries over time in order to operate successfully after their early days in the host county environment. Naturally, entrepreneurial activities of innovative start-ups face higher risks and uncertainties at the outset, as discussed earlier.

Although the cross-sectional methodology of this article's research across 28 European country-environments, using structural equation modeling (SEM), could not examine the specific impact of various environmental characteristics on entrepreneurial orientation and entrepreneurial practices at the local levels in each country context over time, the overall indicators pointed to contextual influences strongly affecting various facets of internationalization and international entrepreneurship. It is noteworthy that the entrepreneurial intentions and orientations of "non-entrepreneurs" that portray their context had a significant positive influence on the creation of entrepreneurial businesses and their internationalizations. In summary, the findings of this research strongly support the notion that the true, or perceived, state of the firms' environment influences

\footnotetext{
${ }^{12}$ EU's five freedoms were ratified by its first 12 members before the end of 1993 and more harmonizing EUwide conventions, such as Maastricht Treaty, Schengen Agreement, and many others, have formalized a relatively harmonized environment in the EU's current 27 member countries.
} 
their strategic management of their regular affairs as well as the management of an emerging or unfolding crisis, regardless of its magnitude and timing.

The fourth article in this issue complements the previous article through a deeper examination of institutional impacts from a women entrepreneurs' perspective. It is entitled "The neglected role of formal and informal institutions in women's entrepreneurship: a multi-level analysis" and is co-authored by Daniela Gimenez-Jimenez, Gimenez-Jimenez, Andrea Calabrò, and David Urbano. This article draws on, and extends, the impact of institutional context, discussed above, to include what the authors termed as "informal institutions' impact on women entrepreneurs." As discussed in the context of European countries earlier, socio-cultural and behavioral aspects of the various societies vary and influence different entrepreneurship initiatives differently. In contrast to the tangible influences and effects of formal institutions, the socio-cultural values of a society remain nearly invisible, but quite influential. What the authors call as neglected "informal institutions" are widely portrayed as a society's "software" by cultural anthropologists, such as Geert Hofstede, among others (Hofstede 1983, 2001, 2011; Hofstede et al. 2010). In contrast to the "hardware" that is structural and tangible, the "software" remains hidden, if not intangible, neglected, and ignored, that it functions consistent with its socio-cultural values and daily behavioral routine, which act as design parameters woven into the software's programs that control social functions quietly. The underlying multi-level research methodology analyzing the entrepreneurial experience of more than 27,000 women in 20 countries in this article suggests that both of the societal formal and informal institutions impact entrepreneurship, and especially women entrepreneurs more significantly and profoundly, and yet they have remained "neglected."

In the context of a major crisis, facing society in general, and entrepreneurial SMEs in particular, the question of how do the formal and informal institutions of a society assist or hamper effective crisis management, especially by women executives, resumes high importance. The casual observation of conditions imposed by the COVID-19 crisis in the past 6 months, or so, suggests that both the society's formal and informal institutions of the affected environments imposed higher expectation, if not more responsibilities, on women than their previous family setting transformed into home and office at the same time, which have adversely affected women's time, effort, and attention in effectively managing their firm's crisis and also attending to their family as they did previously. Assuming that crisis management requires management's more intensive attention and effort than those of normal times, the important question for women executives is, how should the required additional efforts by busier women executives be assisted? And if they cannot be, who should be bearing the additional costs and the consequent damages to both the women's family and their firms? Specifically, what should be the uncodified, but understood, societal expectations of women executives? Are they expected to sacrifice their family's wellbeing or not concentrate fully on managing their enterprises' crisis effectively? ${ }^{13}$ Naturally, the preliminary answer lies in what is consistent with the society's informal sociocultural value systems as well as those formally codified in the society's laws,

\footnotetext{
${ }^{13}$ In favor of full disclosure, I leave in the province of Quebec, Canada, that provides generous formal and informal support to young families and nascent enterprises under distress; but this is not the case elsewhere.
} 
regulations, and broadly accepted behaviors. This discussion provides a socio-cultural bridge to the next article.

The fifth article of this issue is entitled "Market orientation and strategic decisions on immigrant and ethnic small firms" and is co-authored by Eduardo Picanço Cruz, Roberto Pessoa de Queiroz Falcão, and Rafael Cuba Mancebo. As the title suggests, this research is about entrepreneurs facing a new and possibly different environmental context than their familiar previous one at home, thus exposing them to the fear, if not the uncertainty, of unknowns, including the hidden and intangible socio-cultural value systems. They need to decide about their overall strategy, including marketing orientation, in their newly adopted environment. Immigrant entrepreneurs face the challenges of belonging to two environments, one at home, which they left behind, and the other in their unfamiliar new home (the host country), in which they would aim to succeed (Etemad 2018b). When there are significant differences between the two, they face a minor crisis in terms of the uncertainty of if their innate home strategic orientation or that of their host can serve them best. Either of the two strategic choices exposes them to certain uncertain costs and benefits, which are not clear at the time. Naturally, their familiarity with their previous home's socio-cultural environment, within which they feel comfort and may need nearly no new learning and adaptation, pushes them to operate in a similar environment to home to give them certain advantages and possibly lower risks and uncertainties. This orientation attracts them towards their ethnic and immigrant community, or enclave, based primarily on the perception that their ethnic communities, enclaves, and their market segments in their adopted home still resemble their home environment's context, which in turn suggest that they can capitalize on them by relying on their common ethnic social capital (Davidsson and Honig 2003), using their home language, culture, and routine practices with minimal cognitive and psychic pain of adapting to the new context. However, that perception, or assumption, may not be valid or functional, where the society's sociocultural values encourage rapid adaption and change so that immigrants become like other native citizens. Although the market orientation of concentrating on their ethnic community in their adopted country for its advantages, including a lower perceived short-term uncertainty (e.g., Akerlofian type of risk and uncertainty), it may not work or prove to be restrictive in longer term due to, for example, the community may be small, decreasing in size and gradually adapting to their host country prevailing sociocultural values, thus posing an uncertainty of Knightian type, where the future state is difficult to predict.

In contrast, adopting a strategic and market orientation towards attractive market segments of their new home's socio-cultural values and routine practices may expose the young entrepreneurial firm to the other well-documented risks and uncertainties, which are similar to difficulties encountered by firm starting a new operation in a foreign country (Hymer 1967; Johanson and Vahlne 1977, 2009; Zaheer 1995; Zaheer and Mosakowski 1997, among many others). This strategy may also force the nascent firm to compete with the entrenched competition, both of the immigrant and indigenous origins, unless it can offer innovative, or unique, products (or services) similar to other native innovative start-ups. The noteworthy point, and as discussed earlier (in the "Introductions" and "Developmental arguments" sections), the state of the firm's resources and the entrepreneur's (or the firm's top management team's) extent of experience, information, and knowledge may make the difference between the ultimate 
success or mere survival in either of the above strategies. The rich multi-method and longitudinal research methodology of this article over a 6-year period involving interviews, ethnographic observation, and regular data collection among the ethnic and immigrant entrepreneurs in Brazilian enclaves world-wide enabled the authors to offer a conceptual framework and complementary insights based on their findings and experiential knowledge.

In summary, the research supporting articles in this part are both consistent and supportive of arguments presented in "Introductions" and "Developmental arguments." They will also serve as a basis for arguments in the following "Discussions."

\section{Discussions}

As stated in the "Introductions" section, this issue's release would coincide with the world in the midst of the coronavirus pandemic. Initially and on the face of it, the pandemic was perceived as a health-care problem in China followed by other counties in the east and south-east Asia; but it soon turned into a world-wide crisis far-beyond health-care in a few other countries quickly affecting nearly all aspect of the others before inflicting them with the unfolding crises of their own.

Generally, health-care institutions are viewed as the societies' institution of last resort and are expected to deal with potential crises of others, rather than becoming the epicenters of a crisis, posing challenges to others and to their respective societies as a whole. The health-care system in the publicly financed countries is given resources; held in high regard because of their highly capable human resources; ${ }^{14}$ is assumed to be well managed ready to resolve health-care-related problems, if not crises; and consequently expected to effectively solve all health-related challenges as they arise. However, and regardless of their orientation-privately held or publicly supported systems - the health-care system traveled to the brinks of breakdown ${ }^{15}$ and collapse, although they had dealt with similar, but smaller, outbreaks of regional and seasonal flu or other epidemics previously-e.g., the HIV/AIDS outbreak of the late 1970s and now endemic world-wide, SARS epidemic of 2003, and $\mathrm{N}_{1} \mathrm{H}_{1}$ flu of 2009 that became a pandemic, among others, in the near recent memories - but the COVID-19 pandemic overwhelmed them. Retrospectively, the health-care institutions, and the system as a whole, were not the only sector experiencing high levels of systematic fatigue, stress, and strains nearing breakdowns, suggesting that some countries were not prepared to deal with a major crisis. Naturally, less prominent institutions than the country' healthcare system, and subsequently the government alike, were not spared; and many ad-hoc experimental procedures had to be used and valuable lessons had to be learned in hurry in various institutions and many occasions in the hope of saving the moment pregnant with precarious lives and livelihoods. Such rapidly developing phenomena, seemingly beyond control initially, influenced the overall theme of this issue, although already

\footnotetext{
${ }^{14}$ A typical physician has at least 20 years of formal education and training, which put them in the highest levels of highly educated people in advanced countries.

${ }^{15}$ In fields such as, strength of materials and structural design, "metal fatigue" is a topic of notable importance as it may lead to cracks, breakdowns, and possible failure, if not destructions. For example, low-frequency vibrations and frequent thermal expansion and contractions have caused stress concentrations that may eventually cause propagating cracks and eventual failures in airliners and ocean-going freight liners.
} 
accepted articles waiting to be placed in a regular publication were not written on the topic of crisis management. Given the gravity of the COVID-19 pandemic pushing many institutions into their crisis of survival, this issue adopted the overriding thematic topic of crisis management perspective to enable a richer discussion of different components of crisis management with a focus on SMEs and iSMEs based on the specific research of each of the articles accepted through the journal rigorous doubleblind review process.

Expectedly, the resource-constrained small- and medium-sized enterprises (SMEs) and their internationalized counterparts (iSMEs) suffered deeply due to lockdown of their customers, employees, and service providers. Similarly, the sudden stoppage of major national and international economic activities in many advanced countries, including those in the European and American continent, paralyzed them initially as the early impacts were totally unexpected.

The health-care system was not the only sector experiencing dangerous levels of stress and strains. Entertainment hotel and lodging industries, performing and creative arts, hospitality and restaurant industries, and tourism and their complementary goods and service providers, mostly smaller enterprises, among many other SMEs, were caught off-guard and suffered deeply from lack of demand due to rapid economic slow-down, fears of infections, and enforcement of lockdowns in many affected countries. Similarly, integrated manufacturing systems, such as automobile industries, where parts had to arrive from different international sources on time, if not just in time, came to a halt because of the near collapse of international supply chains in addition to national protectionism of the past showing its ugly face after sometimes. Such conditions were not seen for some seven decades, after the Second World War triggering the multi-lateral agreement in Bretton Wood in 1941 to 1947's multi-national conferences that created the world's enduring world institutions such as GATT (replaced by WTO), IMF, and World Bank.

At the socio-cultural and economic levels, the imposed self-isolation and lockdown of cities and communities, to avoid further transmission of the coronavirus to the unsuspecting others, entailed immobility, and the imposition of social distancing disrupted all normal routine behaviors. Many industries could no longer operate as safe social distances could not be provided. ${ }^{16}$ International, national, and even regional travels were shuttered down as national boarders were nearly closed. As a direct result, small- and medium-sized enterprises in the affected industries, who depend on others intensively, suffered a double whammy massively - their demand had collapsed, and their supplies had stopped. Some were ordered closed and others had no reason to operate due to the immobility of employees, customers, and clients alike as well as severe shortages of parts and supplies. Consequently, they had to shut down to minimize unproductive fixed costs. In short, the world has been, and in some cases is still, struggling with the COVID-19 crisis at the time of this writing in June 2020. Only 6 months earlier in December 2019, not many people imagined the emergence of the crisis in their locale, let alone a massive global pandemic, crippling community after community, which revealed deep socio-cultural, economic, and institutional unattended faults. Collectively, they pointed to unpreparedness of many unsuspecting productive

\footnotetext{
${ }^{16}$ Consider for example, work stations on a mass-production assembly line designed for delivering maximum efficiency regardless of workers' distance from each other.
} 
enterprises and institutions alike. In contrast, more far-sighted and conservative institutions with alternative contingency plans based on their relatively minor crisis-like experiences previously, such as transportation and labor strikes, not comparable to COVID-19, activated their relevant contingency plans. Consider, for example, that the alternative of online marketing and sales could compensate for the immobility of customers and in-person sales transactions. Naturally, enterprises with on-line capabilities either gained market shares or suffered less severely.

In short, the overriding lesson of this crisis as discussed in some length in "Developmental arguments" and in "The summary highlight of articles in this issue" and in response to queries raised in "Introductions" is that the institutional under- and unpreparedness, regardless of the level, location, and size, inflicted far higher harms than the incremental costs of carrying alternative contingency plans for the rainy days as evidenced by the considerable success of on-line expansion and quick reconfiguration of flexible manufacturing to accommodate the unexpected oddities of the unfolding crisis.

\section{Conclusion and implications}

Aside from the global scale of the COVID crisis, similar, if not more severe, crises had happened in different locations, some repeatedly, and humanity had suffered and should have learned. Consider, for example, the torrential rains and subsequent flooding and mudslides in the temperate regions; massive snow falls in the Northern Hemisphere shutting down activities for days, if not weeks, at the time; massive earthquakes destroying residential and office buildings without warning (e.g., Christ Church City, New Zealand, the ancient trading city of Baam in southeastern Iran); heavy ice storm in Eastern Canada destroying electrical transmission lines that resulted in shutting down cities for many days; the massive and widespread tsunami of Indian Ocean destroying coastal areas in about 19 countries with quarter-million casualties, among many others, should have served as wake-up calls. While many of the past stricken areas still remain exposed and vulnerable to recurrence, reinforcement and warning systems are in place for a minority of them. For example, the earthquake detection system in the deep seas neighboring tsunami-prone areas has provided ample warning to the vulnerable regions and have avoided major damages. Conversely, the massive tsunami of eastern Japan that destroyed the Fukushima Daichi Nuclear Power Plant in addition to large financial, property, and human losses as well as untold missing persons could have been avoided. In an earthquake-prone country such as Japan, the design faults in the protective barrier walls should have protected the Fukushima Nuclear Power Plant and avoided the release of toxic nucleic emissions. The above discussions point to a few noteworthy lessons and implications as follows:

1 The possibility of recurrence, possibly with higher striking probabilities than before, is not out of the realm of reality, thus calling for planned precautions and, if not adequate, preparations for preparedness.

2 The organs, institutions, and systems weakened by a crisis, regardless of its magnitude and gravity, are in need of rebuilding and re-enforcement to endure the next adverse impacts, which also include SMEs that reached near demise and 
their management systems were nearly compromised by the emerging COVID and its still uncertain unfolding and post-COVID-aftermath.

3 The primary vital support systems, especially the support systems of the last resort, including the first responders, emergency systems, warning and rescue systems, among others, need to develop alternative and functional contingencies and stay near readiness as the timing of the next crisis may remain a true uncertainty (of Knightian type discussed earlier).

4 The immediate support systems, agencies, or persons need to have planned redundancies and ready-to-act as backups should their clients be affected by unforeseen events.

5 Sustainability and resilience need to become an integral part of all contingency plans as the strength of the collectivity depends on the strength and resilience of the weakest link(s) (Blatt 2009).

6 The prevention of a natural disaster of COVID-scale possibly engulfing humanity is in need of supra-national institutions with effective plans, incentives, and sanctions to prevent self-interest at the cost to larger collectivity, if not to the humankind.

The immediate implication of the above discussions in the post-mortem analysis of a crisis, regardless of its scale and magnitude, is to learn about causes and the reason for failure to stop and possibly reverse their effects in a timely fashion. In the context of SMEs and iSMEs, management training, simulation to test the efficacy and reliability of crisis scenarios for alternative contingency plans, and their feasibility and functionality, among others, are of critical importance, which point to the four equally important efforts:

1 Crisis management needs to become an indispensable part of education at all professional levels to enable individuals to protect themselves and assist others in need as well as to reduce the burdens and gravity of the collective harms.

2 The societal backbone institutions and institutional infra-structures on which others depend must be strengthened so that they can stand the impact of the next crisis, regardless of its timing and origin, and support their dependents.

3 The widespread and learned lessons of COVID-19 crisis should be utilized to prepare for a more massive crisis in not so distant future

4 The SMEs, and especially iSMEs, as socio-economic institutions with societal impact need to re-examine their dependencies on others and take steps to avoid their recurrence in ways consistent with their long-term aims and objectives. In the final analysis, the experience of the COVID-19 pandemic indicates that humanity is fragile and only collective actions can provide for the necessary capabilities and resources for dealing with the next potential disaster. Similarly, the smaller institutions that provide for the basic ingredients, parts, and support for the full functioning of their networks and the livelihood of their respective members need the assurance of mutual support in order to survive and to deliver their vital support needed.

On a final note, it is an opportune privilege for the Journal of International Entrepreneurship to take this invaluable opportunity to reflect on the ongoing crisis with the 
ability to still inflict further harm and more damages nearly beyond the control of national governments. Similarly, and on the behalf of the journal, I invite the scholarly community to take up the challenge of educating and preparing us for the next crisis, regardless of its nature, location, and timing. The journal is prepared to offer thematic and special issue(s) covering the management of crisis in SMEs and iSMEs alike.

\section{References}

Akerlof GA (1970) The market for "lemons": quality uncertainty and the market mechanism. Q J Econ 84(3): 488-500

Aparicio S, Urbano D, Audretsch D (2016) Institutional factors, opportunity entrepreneurship and economic growth: panel data evidence. Technol Forecast Soc Chang 102:45-61

Barney J, Wright M, David J, Ketchen DJ (1991) The resource-based view of the firm: ten years after 1991. J Manag 27(2001):625-641

Blatt R (2009) Resilience in entrepreneurial teams: developing the capacity to pull through. Front Entrep Res 29(11):1

Brown AL (2016) Asymmetric information. In: Augier M, Teece D (eds) The Palgrave encyclopedia of strategic management. Palgrave Macmillan, London

Bruton G, Ahlstrom D, Li HL (2010) Institutional theory and entrepreneurship: where are we now and where do we need to move in the future? Enterp Theory Pract 34:421-440

Bylund PL, McCaffrey M (2017) A theory of entrepreneurship and institutional uncertainty. J Bus Ventur 32(5):461-475

Chen MR, Lin HC, Michel JG (2010) Navigating hypercompetitive environment: the role of action aggressiveness and TMT integration. Strateg Manag J 31:1410-1430

Chen J, Saarenketo S, Puumalainen K (2017) Home country institutions, social value orientation, and the internationalization of ventures. Int Bus Rev 27:443-441. https://doi.org/10.1016/j.ibusrev.2017.09.011

Chiles TH, Bluedorn AC, Gupta VK (2007) Beyond creative destruction and entrepreneurial discovery: a radical Austrian approach to entrepreneurship. Organ Stud 28:467-493. https://doi.org/10.1177 /0170840606067996

Coff RW (1999) How buyers cope with uncertainty when acquiring firms in knowledge-intensive industries: caveat emptor. Organ Sci 10(2):144-161

Davidsson P, Honig B (2003) The role of social and human capital among nascent entrepreneurs. J Bus Ventur 18(3):301-331. https://doi.org/10.1016/S0883-9026(02)00097-6

Dimov D (2018) Uncertainty under entrepreneurship. In: Fayolle A, Ramoglou S, Karatas-Özkan M

Dow SC (2012) Uncertainty about uncertainty. Foundations for new economic thinking. Palgrave, In

Eisenhardt KM, Martin JA (2000) Dynamic capabilities: what are they? Strateg Manag J 21(10-11):1105-1121

Eriksson JJ, Majkgård A, Sharma DD (1997) Experiential knowledge and cost in the internationalization process. J Int Bus Stud 28(1997):337-360

Erikson T, Korsgaard S (2016) Knowledge as the source of opportunity. J Bus Ventur Insights 6:47-50

Etemad H (2018a) Early strategic heritage: the carryover effect on entrepreneurial firm's life cycle. J Int Entrep $16(4$ (Fall 2018)):441-455. https://doi.org/10.1007/s10843-018-0240-9 https://link.springer. com/content/pdf/10.1007\%2Fs10843-018-0240-9.pdf

Etemad H (2018b) Advances and challenges in the evolving field of international entrepreneurship: the case of migrant and diaspora entrepreneurs. J Int Entrep 16(2):109-118. https://doi.org/10.1007/s10843-018-0233-8

Etemad H (2019) Actions, actors, strategies and growth trajectories in international entrepreneurship. J Int Entrep 17(2):1-17. https://doi.org/10.1007/s10843-019-00251-6

Etemad H (ed.) (2020) Management of crisis by SMEs around the world. Elgar Pblishing, Northhampton, Mass. (Forthcoming in 2020)

Gartner WB, Liao J (2012) Risk-takers and taking risks. In: Chance and intent. Routledge, Abingdon, pp 33-48

Granovetter M (1985) Economic action and social structure: the problem of embeddedness. Am J Sociol 1985: $481-510$

Hannibal M (2020) The influence of additive manufacturing on early internationalization: considerations into potential avenues of IE research. J Int Entrep. https://doi.org/10.1007/s10843-019-00267-y

Hofstede G (1983) The cultural relativity of organizational practices and theories. J Int Bus Stud 14:75-89 
Hofstede G (2001) Culture's consequences: comparing values, behaviors, institutions and organizations across nations. Sage Publications Inc, Thousand Oaks

Hofstede G (2011) Dimensionalizing cultures: the Hofstede model in context. Online Readings Psychol Cult 2:8

Hofstede G, Hofstede GJ, Minkov M (2010) Cultures and organizations: software of the mind vol 3. McGrawHill, London

Huang L, Pearce JL (2015) Managing the unknowable: the effectiveness of early-stage investor gut feel in entrepreneurial investment decisions. Adm Sci Q 60(4):634-670

Huff AS, Milliken FJ, Hodgkinson GP, Galavan RJ, Sund KJ (2016) A conversation on uncertainty in managerial and organizational cognition. In: Uncertainty and strategic decision making. Emerald Group Publishing Limited, Bingley, pp 1-31

Hymer SH (1967) The international operations of national firms: a study of direct foreign investment. MIT Press, Cambridge (a 1960 doctoral thesis published in 1976)

Jantunen A, Puumalainen K, Saarenketo S, Kyläheiko K (2005) Entrepreneurial orientation, dynamic capabilities and international performance. J Int Entrep 3(3):223-243

Jepperson R (1991) Institutions, institutional effects, and institutionalism. In: Powell W, DiMaggio PJ (eds) The new institutionalism in organizational analysis. University of Chicago Press, Chicago, pp 143-163

Johanson J, Vahlne J-E (1977) The internationalization process of a firm - a model of knowledge foreign and increasing market commitments. J Int Bus Stud 8:23-32

Johanson J, Vahlne JE (2009) The Uppsala internationalization process model revisited: from liability of foreignness to liability of outsidership. J Int Bus Stud 40(3):411-421

Knight FH (1921) Risk, uncertainty and profit. A.M. Kelley, New York

Kostova T (1997) Country institutional profiles: concept and measurement. Academy of Management Proceedings, In, pp 180-184

Li Y, Zahra SA (2012) Formal institutions, culture, and venture capital activity: a cross-country analysis. J Bus Ventur 27:95-111

Liesch PW, Welch LS, Buckley PJ (2014) Risk and uncertainty in internationalisation and international entrepreneurship studies. The multinational enterprise and the emergence of the global factory. Palgrave Macmillan, Basingstoke, In, pp 52-77

Matanda MJ, Freeman S (2009) Effect of perceived environmental uncertainty on exporter-importer interorganizational relationships and export performance improvement. Int Bus Rev 18:89-107. https://doi. org/10.1016/j.ibusrev.2008.12.004

McGrath RG, MacMillan IC, Scheinberg S (1992) Elitists, risk-takers, and rugged individualists? An exploratory analysis of cultural differences between entrepreneurs and non-entrepreneurs. J Bus Ventur $7: 115-135$

McKelvie A, Haynie JM, Gustavsson V (2011) Unpacking the uncertainty construct: implications for entrepreneurial action. J Bus Ventur 26(3):273-292

McMullen JS, Shepherd DA (2006) Entrepreneurial action and the role of uncertainty in the theory of the entrepreneur. Acad Manag Rev 31(1):132-152

Mitchell RK, Smith B, Seawright KW, Morse EA (2000) Cross-cultural cognitions and the venture creation decision. Acad Manag J 43:974-993

Noguera M, Alvarez C, Urbano D (2013) Socio-cultural factors and female entrepreneurship. Int Entrep Manag J 9:1-15

North DC (1990) Institutions, institutional change and economic performance. Cambridge university press, Cambridge OECD (2015) OECD family database. OECD, Paris

Stinchcombe AL (1965) Social structure and organizations. In: March J (ed) Handbook of organizations. Rand McNally, Chicago, IL, pp 142-193

Surico P, Galeotti A (2020) The economics of a pandemic: the case of Covid-19. European Research Centre, London Business School, London

Townsend DM, Hunt RA, McMullen JS, Sarasvathy SD (2018) Uncertainty, knowledge problems, and entrepreneurial action. Acad Manag Ann 12(2):659-687

Utterback JM, Acee HJ (2005) Disruptive technologies: an expanded view. Int J Innov Manag 09(01):1-17. https://doi.org/10.1142/S136391960500116217

Wang CL, Altinay L (2012) Social embeddedness, entrepreneurial orientation and firm growth in ethnic minority small businesses in the UK. Int Small Bus J 30(1):3-23

Welter F (2011) Contextualizing entrepreneurship — conceptual challenges and ways forward. Enterp Theory Pract 35:165-184

Welter F, Smallbone D (2011) Institutional perspectives on entrepreneurial behavior in challenging environments. J Small Bus Manag 49:107-125A

Wernerfelt B (1984) Resource-based view of the firm. Strateg Manag J 5:171-180 
Wernerfelt B (1995) The resource-based view of the firm: ten years after, vol 16, pp 171-174 First published. https://doi.org/10.1002/smj.4250160303

Williamson OE (1981) The economics of organization: the transaction cost approach. Am J Sociol 87(3):548-577

Williamson OE (2000) The new institutional economics: taking stock, looking ahead. J Econ Lit 38:595-613

Yousafzai SY, Saeed S, Muffatto M (2015) Institutional theory and contextual embeddedness of women's entrepreneurial leadership: evidence from 92 countries. J Small Bus Manag 53:587-604

Zaheer S (1995) Overcoming the liability of foreignness. Acad Manag J 38(2):341-363

Zaheer S, Mosakowski E (1997) The dynamics of the liability of foreignness: a global study of survival in financial services. Strateg Manage J 18:439-464

Publisher's note Springer Nature remains neutral with regard to jurisdictional claims in published maps and institutional affiliations. 